\title{
Blue Led Light in Burns: A New Treatment's Modality
}

Keywords: Wounds; Healing process; Photobiomodulation therapy; Hard to heal burns

\begin{abstract}
The management of full-thickness severe burns is an important issue from the medical point of view, especially when the autologous skin is not able to engraft on the wound area and, in turn, to induce its re-epithelialization. As a consequence, the wound healing process occurs slowly, by second intention leading to an increased formation of scar tissue. The delay in wound healing leads to a longer management of the patient, increasing inconveniences and increasing the costs for the health system. In addition, comorbidity factors of the patients such as diabetes, infections or its elderly age can also affect the healing process.
\end{abstract}

With the aim to improve the wound bed as well as the healing time, we decided to test photobiomodulation therapy (PBMT) as a new practice for the burn-care treatment. The results here reported show its effectiveness in the promotion of wound healing leading to faster and better final aesthetic results.

\section{Abbreviations}

PBMT: Photobiomodulation Therapy

\section{Introduction}

Burns is a type of acute trauma affecting millions of people worldwide that frequently occurs for an incidental/intentional exposure to fire as well as a wrong use of inflammable liquids [1]. The therapeutic strategy used to manage burned patients is related to the severity, depth and anatomic area of the burn and the clinical condition of the patient. In fact, a spontaneous re-epithelialization of the wound area is expected up to a superficial/medium seconddegree burn, while the removal of necrotic tissue and the replacement of skin defect with autologous skin is performed on burns of deep second/ third degree [2-4]. However, the engraftment of autologous skin on the damaged area is not always guaranteed and its partial/ total detachment from lesion leads to a delayed healing process by second intention further affected by patient's comorbidities. Among the different approaches developed to stimulate wound healing, the use of PBMT appears to be very promising. The underlying mechanism of this new therapy is a photothermal effect, due to the selective absorption of the blue light by the hemoglobin - in particular the heme group - in the bleeding wound able to improve the healing process, with an apparent modulation of the fibroblast activity and better recovery of the collagen content in the wound area. The direct light energy transfer from the device to the patient permits the interaction and the stimulation of some chromophores of blood and skin, in particular cytochrome $\mathrm{C}$ and protoporphryn IX. Once activated by the blue light, cytochrome $\mathrm{C}$ interacts with the last two mitochondrial transport chain complexes and contributes to strengthening the cellular respiratory process, increasing the production of adenosine triphosphate, energy currency of the cell, which can intensify its metabolic activity. A further important effect is an increased production of reactive oxygen species (ROS),

\section{Journal of}

\section{Clinical \& Investigative Dermatology}

\author{
Orlandi C, Purpura V* and Melandri D \\ Burns Centre, Dermatology and Emilia Romagna Regional Skin Bank, M. \\ Bufalini Hospital, Italy
}

\section{*Address for Correspondence}

Purpura V, Burns Centre, Dermatology and Emilia Romagna Regional Skin Bank, M. Bufalini Hospital, Viale Ghirotti 286, 47522 Cesena (FC), Italy; Fax: 39 0547 394327; Tel: 390547 352919; Email: Valeria.Purpura@Auslromagna.It

Submission: 27 July, 2021

Accepted: 30 August, 2021

Published: 05 September, 2021

Copyright: $\odot 2021$ Orlandi C, et al. This is an open access article distributed under the Creative Commons Attribution License, which permits unrestricted use, distribution, and reproduction in any medium, provided the original work is properly cited.

signal transducers of numerous cellular pathways in tissue repair; an increased production of ROS induces a controlled increase of inflammatory functions sufficient for stimulating tissue response [5-7]. Although the mechanism underlying photobiomodulation is still not completely understood, it has accumulated evidences of a positive action on all phases of wound repair, from inflammation to remodeling.

These beneficial effects include acceleration of wound healing, cellular and extracellular matrix proliferation, collagen production and granulation tissue formation [8]. It also shows anti-microbial activity [9] leading to synergic, beneficial effects on healing process. Important scientific literature supports the evidence that light stimulates tissue regeneration and skin repair owing to its ability to interact with tissue inducing the photobiomodulation [10]. Previous studies show how PBMT is able to promote metabolism of all cellular processes by ATP synthesis and, in turn, to stimulate angiogenesis [11], tissue repair with reduction of scar tissue and formation of keloids [12]. To date, the use of blue light with a low frequencies range of 400-450 nm results to be effective for the treatment of different dermatologic pathologies such as acne [13-15], psoriasis [16] and eczema [17] as well as skin wounds [18-19]. For all these advantages, the use of PBMT is now increasing in clinical practice to improve wound bed as well as the healing time.

In this study, we evaluated for the first time the effectiveness of this treatment both in burned patients not able for surgery for their comorbidities and those in which skin engraftment failed, in order to promote the healing process. Our results lead us to consider PBMT an effective new burn- care approach available in the clinical practice of burn-care.

\section{Material and Methods}

The observations were made on 11 patients ( 4 females and 7 males) with burns resistant to standard treatment then treated with PBMT in order to promote the skin lesion healing. In particular, 9 patients showed deep burns of different etiologies not responding to surgery with skin grafts while the other 2 patients showed skin scarring treated with dermo-epidermal substitutes with incomplete re-epithelialization. 
To perform PBMT, we used a portable medical device emitting blue light with a wavelength of between 400 to $430 \mathrm{~nm}$; it was applied for one minute/application at a distance of $4 \mathrm{~cm}$ from the wound bed, providing it a LED radiation of $120 \mathrm{~mW} / \mathrm{cm}^{2}$ power density, which corresponds to an energy density dose of $7,2 \mathrm{~J} / \mathrm{cm}^{2}$; light covered a circular $5 \mathrm{~cm}$ diameter area so that application numbers were correlated to wound size. The treatment schedule adopted was the application of blue LED light for 60 seconds twice a week for a maximum period of ten weeks at the time of dressing change and after wound cleaning with distilled water. Following the blue LED light treatment, appropriate dressing for the type of lesion was applied according to the required standard. This treatment does not interfere with other systemic therapies that may be in place and does not involve any additional risk compared to standard treatment; the comparative evaluation of aesthetic outcomes was performed using modified Yeong scale (Table 2).

\section{Results}

In our study, we selected patients with burns resistant to standard treatment candidates to alternative, not invasive approaches such as PBMT. In particular, we mainly evaluated data of the patients treated reported in Table 1. The treatment was well tolerated, there were no reports of side effects or other adverse events and compliance was excellent. The patients recorded a significant reduction in pain at the end of the treatment period. We witnessed the reactivation of the reparative process with the complete re-epithelialization of the burns or of the burned area where the autologous graft was not successful in 8 cases out of [11]. In 2 cases we observed a percentage reduction of the lesion area of at least $80 \%$ compared to the initial one. In only 1 case there was a poor response to the treatment probably due to the extreme severity of the initial picture and the consequent severe physical deterioration of the patient.

We describe below three cases particularly interesting from a clinical point of view, for the results obtained given the initial lesion conditions.

\section{Clinical case 1}

The first patient we treated with blue LED light was a 67 year old man with cirrhosis and psoriasis. He presented deep burns of the abdomen (Figure 1A) treated with surgery with the application of autologous skin grafts then failed (Figure 1B). Thus, we decided to use PBMT to promote the healing process. In this case, five applications twice a week were required to obtain the wound healing, according to the protocol described in material and methods (Figure 1C, detail Figure 1 C-1).

Surprisingly, we observed a marked improvement of the wound bed after only three treatments as well as a reduction of lesion's depth and inflammation, exudation and re-epithelialization (Figure 1D).

The wound bed at the end of the treatments showed a complete reepithelialization with focal atrophic areas, without an inflammatory response (Figure $1 \mathrm{E}$ ) and the clinical follow-up after 3 and 14 months showed a scarcely erythematous and hypertrophic scarring, not retracting and soft to the touch. The atrophic areas were also significantly reduced (Figure1 F-G).

\section{Clinical case 2}

The second patient was a 61 year old man with deep burn of shoulder (Figure 2A) treated with surgery with the application of autologous skin grafts then failed (Figure 2B). Although a new surgery was recommended, the patient refuse it. Thus, we decided to use PBMT to promote the healing process. In this case, eight applications twice a week were required to obtain the wound healing. We quickly observed a revitalization of the wound bed, with reduction of slough and clean base, normal exudate and proliferative edges already after 3 treatments (Figure 2C) with a flat scarring, soft to the touch, pink in color and with the presence of fine superficial telangiectasias in the follow-up after 1 months (Figure 2D).

\section{Clinical case 3}

The third patient was a 59 year old woman suffering from

Table 1: Schematic representation of the main data of the patients treated with blue LED light.

\begin{tabular}{|c|c|c|c|c|c|c|c|}
\hline PATIENT & AGE & SEX & COMORBIDITIES & $\%$ BURN & SITE TREATED & $\begin{array}{c}\% \text { RE-EPITHELIALIZATION } \\
\text { ACHIEVED }\end{array}$ & $\begin{array}{l}\text { NUMBERS OF } \\
\text { TREATMENT }\end{array}$ \\
\hline 1 & 67 & M & Cirrhosis, psoriasis & $15 \%$ & Abdomen (Graft failed) & Healed $(100 \%)$ & 5 \\
\hline 2 & 61 & M & Poor compliance & $2 \%$ & Shoulder (Graft failed) & Healed $(100 \%)$ & 8 \\
\hline 3 & 59 & $\mathrm{~F}$ & Hypertension & $30 \%$ & $\begin{array}{l}\text { Right arm } \\
\text { (Graft failed) }\end{array}$ & Healed $(100 \%)$ & 4 \\
\hline 4 & 76 & M & Hypertension, hyperuricemia & $15 \%$ & $\begin{array}{l}\text { Head (refused } \\
\text { surgery) }\end{array}$ & Healed $(100 \%)$ & 8 \\
\hline 5 & 61 & $\mathrm{~F}$ & $\begin{array}{l}\text { Polyallergic, gastric ulcer, } \\
\text { hypercolesterole mia }\end{array}$ & $30 \%$ & Thighs (Graft failed) & $80 \%$ & 10 \\
\hline 6 & 61 & $\mathrm{~F}$ & epilepsy & $40 \%$ & $\begin{array}{l}\text { Left hemithora x (Graft } \\
\text { failed) }\end{array}$ & $90 \%$ & 10 \\
\hline 7 & 28 & M & /l & $70 \%$ & $\begin{array}{l}\text { Graft failed } \\
\text { No healing site (thighs, } \\
\text { shoulder) }\end{array}$ & $20 \%$ & 5 \\
\hline 8 & 90 & $\mathrm{~F}$ & $\begin{array}{l}\text { Hypertension, pace maker, } \\
\text { BPCO, gastric ulcer, arrhythmia, } \\
\text { depression }\end{array}$ & $25 \%$ & post nexobride (Graft failed) & Healed $(100 \%)$ & 5 \\
\hline 9 & 52 & M & // & $25 \%$ & Ear (No healing site) & Healed $(100 \%)$ & 3 \\
\hline 10 & 28 & M & /l & $\begin{array}{c}\text { Scarrin g with ulcers right } \\
\text { arm }\end{array}$ & No healing site (Graft failed) & Healed $(100 \%)$ & 3 \\
\hline 11 & 74 & M & Hypertension & $\begin{array}{c}\text { Scarrin g with ulcers right } \\
\text { leg }\end{array}$ & No healing site (Graft failed) & Healed $(100 \%)$ & 12 \\
\hline
\end{tabular}


Table 2: Scar score of modified Yeong scale. Each category is assigned a score from 1-4, for atotal possible score of 3-12.

\begin{tabular}{|c|c|c|c|c|}
\hline & $\mathbf{1}$ & $\mathbf{2}$ & $\mathbf{3}$ \\
\hline $\begin{array}{c}\text { Scar surface } \\
\text { appearance }\end{array}$ & $\begin{array}{c}\text { Scar surface appears similar } \\
\text { to normal skin }\end{array}$ & $\begin{array}{c}\text { Slight mismatch. Scar surface appears } \\
\text { smoother or rougher than normal skin }\end{array}$ & $\begin{array}{l}\text { Noticeably rougher than normal } \\
\text { skin. Shallow depressions and } \\
\text { irregularities within scar }\end{array}$ & $\begin{array}{c}\text { Scar surface appears very rough } \\
\text { compared to normal skin. Deep } \\
\text { depressions and irregularities. Loss } \\
\text { of normal architecture. }\end{array}$ \\
\hline Scar height & $\begin{array}{c}\text { No difference. Scar surface } \\
\text { at the same plane as normal } \\
\text { skin }\end{array}$ & $\begin{array}{c}\text { Slight difference. Smooth slope at the edge } \\
\text { of the scar (positive or negative) }\end{array}$ & $\begin{array}{c}\text { Moderate difference. Defined } \\
\text { slope at the edge of the } \\
\text { scar (positive or negative) }\end{array}$ & $\begin{array}{c}\text { Extreme difference. Abrupt dropping } \\
\text { at the edge of the scar (positive or } \\
\text { negative). }\end{array}$ \\
\hline Color mismatch & $\begin{array}{c}\text { Minimal color difference. } \\
\text { Difficult to distinguish }\end{array}$ & $\begin{array}{c}\text { Slight color difference. Subtle } \\
\text { but noticeable (includes differences in } \\
\text { pigmentation or erythema) }\end{array}$ & $\begin{array}{c}\text { Moderate color difference. } \\
\text { Easy to distinguish (includes } \\
\text { differences in pigmentation or } \\
\text { erythema) }\end{array}$ & $\begin{array}{c}\text { Major color difference. Prominent } \\
\text { mismatch (includes differences in } \\
\text { pigmentation or erythema) }\end{array}$ \\
\hline
\end{tabular}

Table 3: Aesthetic results of the burns (clinical cases 3) treated or not with blue LED light at 9month.

\begin{tabular}{|c|c|c|}
\hline & Right upper limb & Lower limb \\
\hline Scar surface appearance & 2 & 4 \\
\hline Scar thickness & 2 & 4 \\
\hline Color mismatch & 1 & 2 \\
\hline & 5 & 10 \\
\hline
\end{tabular}

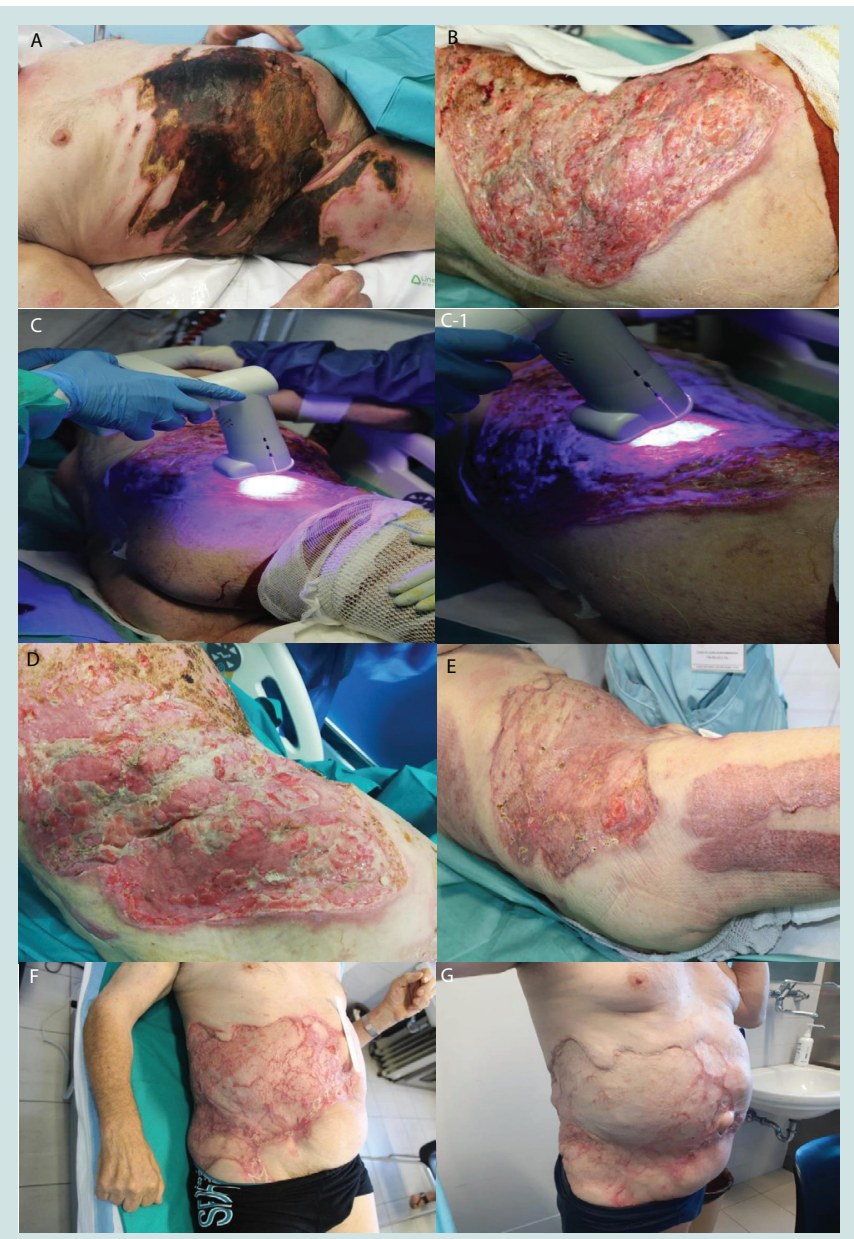

Figure 1: Clinical case 1 treated with blue LED light. A,B: Deep burns of the abdomen at the admission Burns after surgical treatment and the application of autologous skin grafts then failed. C, C-1: Beginning of the Blue LED light treatment. Magnification of the Blue LED light treatment on the lesion area. D: Improvement of the wound bed after 3 treatments with a reduction of lesion's depth and inflammation, exudation and re-epithelialization. E: End of treatment. F,G: Follow-up after 3 and 14 months.

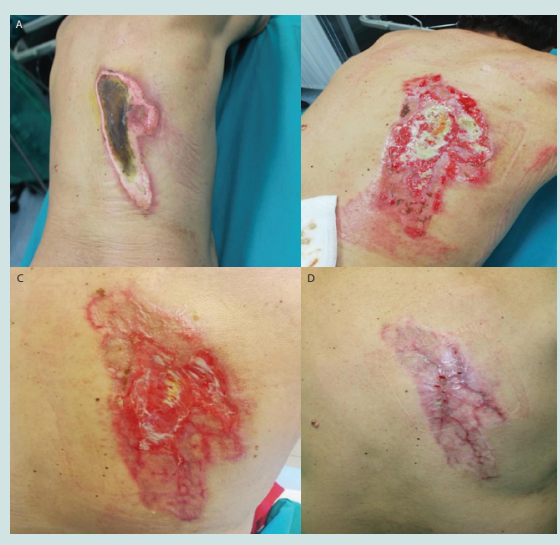

Figure 2: Clinical case 2 treated with blue LED light. A: Deep burn of the shoulder at the admission. B,C: Burns after surgical treatment and the application of autologous skin grafts then failed. Improvement of the wound bed after 3 treatments. D: The clinical follow-up after 1 month.

hypertension. She presented deep burns of the right upper and lower limb (Figure 3A) treated with surgery with the application of autologous skin grafts then failed only on the arm (Figure 3B). We initially treated this area with advanced dressing (Figure $3 \mathrm{C}$ ) but given the slow response we decided to use the PBMT to promote the healing.

In most clinical cases, we also noticed that the use of blue LED light induced a modulation of fibroblast's activity, so as to reduce the possibility of the appearance of keloids or hypertrophic scars keloid recurrence. Thus, in some cases we have also taken into account the aesthetic results, identified as the scar surface appearance, scar height and color mismatch of wounds after 6 and $12-14$ months after hospitalization/healing according to parameters of the modified Yeong scale (Table 2). In particular, we could compare at 9 months the aesthetic outcomes obtained in the clinical case 3 treated with blue LED light on the right upper limb in which graft skin failed (Figure $3 \mathrm{~F}-\mathrm{G}$ ) and those of the lower limb (Figure $3 \mathrm{H}$ ) in which the engraftment of skin after surgery was evident (Table 3). Based on the clinical evaluation and the score obtained using the modified Yeong scale, we can conclude that the area treated with blue LED light has had a more favorable evolution in terms of scar outcome (thickness, discoloration and consistency of the tissue) than the area treated in a standard way.

\section{Discussion}

Surgical procedure of autologous graft is performed as the 


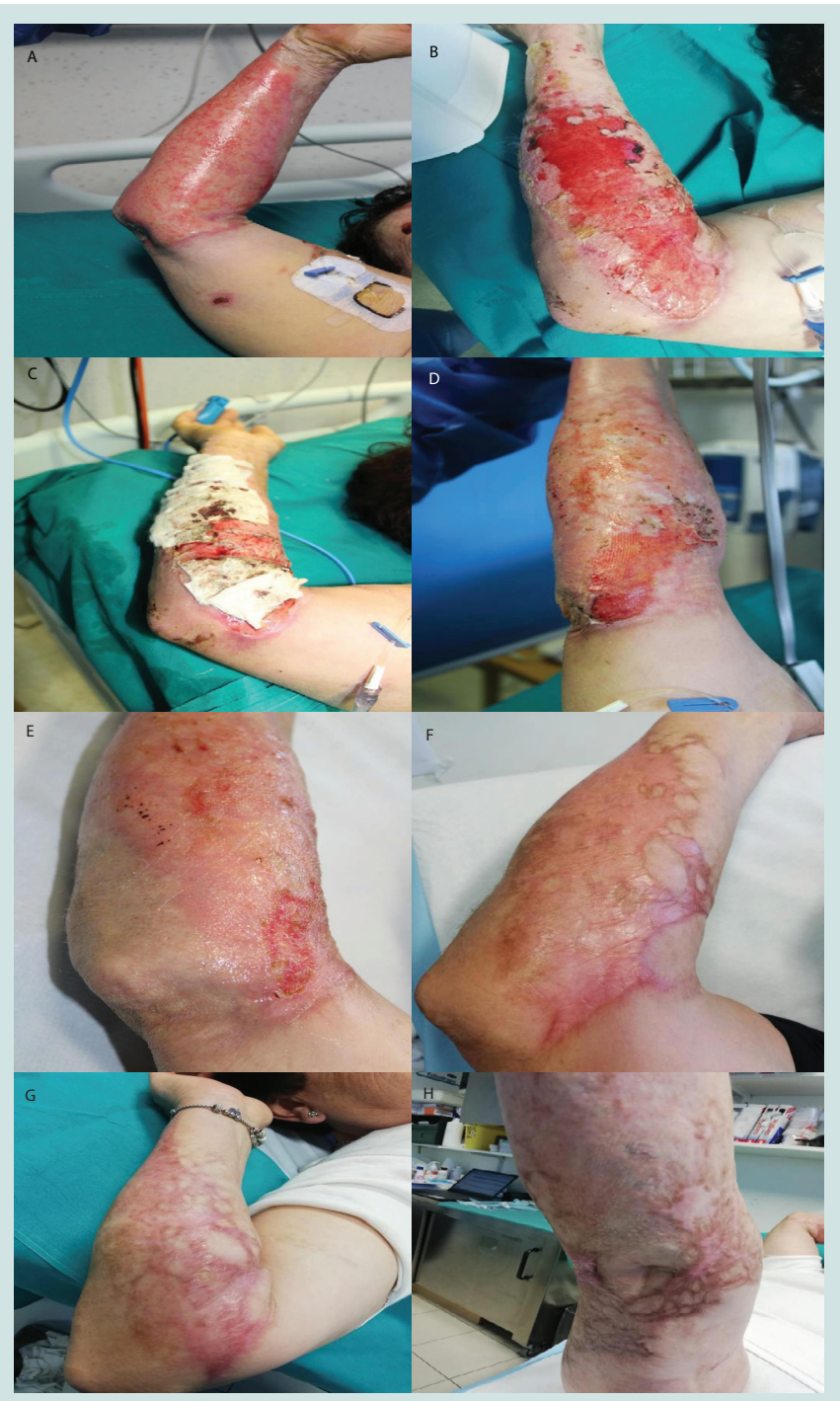

Figure 3: Clinical case 3 treated with blue LED light. A: Deep burn of the right upper limb at the admission. B: Burn of the right upper limb after surgical treatment and the application of autologous skin grafts then failed. C: Burn of the right upper limb after failed grafts treated with advanced dressings. D,E: Spontaneous re-epithelialization of the wound after 2 and 4 , treatments twice a week. F,G: Clinical follow-up after 6 and 9 months. Aesthetic results of right upper limb treated with blue LED light. $\mathbf{H}$ : Those of the lower limb with grafted skin after surgery.

standard of care (SOC) for burns; the coverage of a deep burn with the graft may be immediate, delayed for a few days after the excision or late, after a first phase of direct healing. However, the autologous graft has a probability of failure with total or partial detachment of the grafted skin. When it happens, the healing process of the lesion occurs by secondary intention but it is not always easy to manage, as this process can be delayed or stopped by many factors such as diabetes, infections, metabolic deficiencies and the advanced age of the subject. Although SOC appears to be effective in the most of clinical cases, it results invasive, not selective for necrotic tissue and not always easily practicable for clinical and organizational problems; moreover, the critical conditions of the patients or the presence of comorbidities can be real contraindications to surgical approach. For this reasons, minimally or not invasive approaches have been considered as additional therapies able to reduce the possible side effects related to surgery. In fact, a proper wound management and dressing of burn instead of or after surgery is an important part of the healing process, in order to prevent the onset of infections or other complications, and also to accelerate the wound healing with as little scarring as possible. Among the not invasive approaches used for the burns management, photobiomodulation is a new therapy for treating hard to heal wounds. To the best of our knowledge there are not trials or studies that have analyzed photobiomodulation's effects on burns so this is the first case series. The benefits identified in our clinical cases can be attributable not only to a reactivation of the tissue repair process but also to a reduced healing time and an improvement in scarring, with the consequent indirect benefits, namely reduction of public health expenditure, improvement of quality of the life of patients with burn scars that often significantly impact this parameter. According to our small experience, the blue LED light used for PBMT contributed significantly to a faster healing process, a reduction of inflammatory response and pain as well as better recovered skin morphology.

\section{Conclusions}

Based on our observation, we can conclude that PBMT can be proposed as a promising therapy to be used in the management of cutaneous fibrosis, likely in combination with pre-existing treatments. Patient consent statement: the patients' informed consent was acquired for all patients involved in the study.

\section{References}

1. Peck MD (2011) Epidemiology of burns throughout the world. Part I: Distribution and risk factors. Burns J Int Soc Burn Inj 37: 1087-1000.

2. Reinke JM, Sorg H (2012) Wound repair and regeneration. Eur Surg Res 49: 35-43,

3. Orgill DP, Ogawa R (2013) Current methods of burn reconstruction. Plast Reconstr Surg 131: 827-836.

4. Kagan RJ, Peck MD, Ahrenholz DH, Hickerson WL, Holmes J IV (2013) Surgical management of the burn wound and use of skin substitutes: an expert panel white paper. J Burn Care Res 34: 60-79.

5. Landen NX, Li D, StahleM (2016) Transition from inflammation to proliferation: a critical step during wound healing. Cell Mol Life Sci 73: 3861-3885.

6. Naik E, Dixit VM (2011) Mitochondrial reactive oxygen species drive proinflammatory cytokine production. J Exp Med 208: 417-420.

7. Zadeh MS, Kolb JP, Geromin D, Anna RD, Boulmerka A, et al (2000) Regulation of ICAM-1/CD54 expression on human endothelial cells by hydrogen peroxide involves inducible NO synthase. J Leukoc Biol 67: 327- 334.

8. Prindeze NJ, Moffat LT, Schupp JW (2012) Mechanism of action for light therapy. A review of molecular interactions. Exp Biol Med 237: 1241-1248.

9. Fischer MR, Abel M, Lopez Kostka S, Rudolph B, Becker D (2013) Blue light irradiation suppresses dendritic cells activation in vitro. Exp Dermatol 22 . 558-560.

10. AndersJJ, Lanzafame RJ, Arany PR (2015) Low-level light/laser therapy versusphotobiomodulation therapy. Photomed Laser Surg 33: 183184.

11. Ankri R, Friedman H, Savion N, Kotev-Emeth S, Breitbart H (2010) Visible light induces nitric oxide (NO) formation in sperm and endothelial cells. Lasers Surg Med 42: 348-352.

12. Enwemeka CS (2004) Therapeutic light. Review Rehab Manag 17: 20-25.

13. Dai T, Gupta A, Murray CK, Vrahas MS, Tegos GP (2012) Hamblin MR. Blue light for infectious diseases: Propionibacterium acnes, Helicobacter pylori, and beyond? Review Drug Resist Updat 15: 223-236. 
14. Noborio R, Nishida E, Kurokawa M, Morita A (2007) A new targeted blue light phototherapy for the treatment of acne. Photodermatol Photoimmunol Photomed 23: 32-34

15. Glitzner E, Korosec A, Brunner PM, Drobits B, Amberg N (2014) Specific roles for dendritic cell subsets during initiation and progression of psoriasis. EMBO Mol Med 6: 1312-1327.

16. Félix Garza ZC, Liebmann J, Born M, Hilbers PAJ, van Riel NAW (2017) A Dynamic Model for Prediction of Psoriasis Management by Blue Light Irradiation. Front Physiol 8: 28.

17. Keemss K, Pfaff SC, Born M, Liebmann J, Merk HF (2016) Prospective,
Randomized Study on the Efficacy and Safety of Local UV-Free Blue Light Treatment of Eczema. Randomized Controlled Trial Dermatology 232: 496502.

18. Dungel P, Hartinger J, Chaudary S, Slezak P, Hofmann A (2014) Low leve light therapy by LED of different wavelength induces angiogenesis and improves ischemic wound healing. Comparative Study Lasers Surg Med 46: $773-780$.

19. Cicchi R, Rossi F, Alfieri D, Bacci S, Tatini F (2016) Observation of an improved healing process in superficial skin wounds after irradiation with a blue- LED haemostatic device. J Biophotonics 9: 645-655. 